\title{
WAKTU TANAM PADI SAWAH RAWA PASANG SURUT PULAU KALIMANTAN DI TENGAH PERUBAHAN IKLIM
}

\section{Cropping Time of Tidal Swamp Paddy in Kalimantan Island Facing the Climate Change}

\author{
Nur Wakhid*1 dan Haris Syahbuddin ${ }^{2}$ \\ ${ }^{1}$ Balai Penelitian Pertanian Lahan Rawa \\ J1. Kebun Karet, Loktabat Utara, Banjarbaru 70712 \\ ${ }^{2}$ Balai Penelitian Agroklimat dan Hidrologi \\ Jl. Tentara Pelajar No. 1A Bogor 1611 \\ *Alamat Korespondensi: n_wakhid@yahoo.com
}

\begin{abstract}
ABSTRAK
Salah satu faktor penentu keberhasilan budidaya pertanian di lahan rawa pasang surut adalah waktu tanam. Waktu tanam tanaman pangan terutama padi mempunyai peranan yang sangat penting pada produksi akhir hasil pertanian. Di Indonesia saat ini dikenal 3 Musim Tanam, yaitu musim hujan, antara bulan November-Pebruari, musim kemarau I, antara bulan Maret-Juni; dan musim kemarau II, antara bulan Juli-Oktober. Akan tetapi, dinamika perubahan iklim seperti kekeringan (El Nino) dan kebasahan (La Nina) yang tidak menentu, berimbas pada pergeseran awal dan akhir musim tanam serta berdampak negatif bagi produktivitas tanaman padi. Adanya hal tersebut, analisis tentang waktu tanam padi di lahan rawa pasang surut Pulau Kalimantan perlu dilakukan. Waktu tanam di lahan pasang surut dimulai setelah jumlah air hujan mencukupi untuk melarutkan kadar besi yang ada di dalam air. Realisasi tanam di Provinsi Kalimantan Barat umumnya terjadi pada Dasarian 28 (Oktober), Kalimantan Timur pada Dasarian 31 (November), serta Kalimantan Selatan dan Kalimantan Tengah pada Dasarian 7 (Maret). Waktu tanam di lahan rawa pasang surut menunjukkan tingkat kekukuhan yang tinggi terhadap perubahan iklim, dimana waktu tanam tidak terlalu berubah selama 10 tahun pada kondisi iklim yang berbeda.
\end{abstract}

Kata kunci: dasarian, luapan, air hujan, kekukuhan

\begin{abstract}
One of the critical factors for agricultural cultivation in tidal swamp land is cropping time. Paddy cropping time has a very important role in the final production of agricultural cultivation. Currently, there are 3 cropping time in Indonesia, in the rainy season (November to February), first of dry season (March to June), and second of dry season, (July to October). However, the climate change dynamic such as drought (El Nino) and wetness (La Nina), shifting the cropping time and resulting a negative impact on the productivity of paddy rice. Therefore, an analysis of the rice cropping time needs to be done on Kalimantan tidal swampland area. Cropping time in the tidal swampland area began after the amount of rain was sufficient to dissolve the levels of iron in water. In West Kalimantan, the cropping time realization generally occurs in Dasarian 28 (October), while East Kalimantan on Dasarian 31 (November), and South Kalimantan and Central Kalimantan on Dasarian 7 (March). Cropping time in tidal swamp land showed a high level of resistance to climate change, in which planting time did not change for 10 years in different climatic conditions.
\end{abstract}

Key words: decadal, tidal, rainwater, substantiality

\section{PENDAHULUAN}

Rawa merupakan wadah air beserta air dan daya air yang terkandung di dalamnya, tergenang secara terus menerus atau musiman, terbentuk secara alami di lahan yang relatif datar atau cekung dengan endapan mineral atau gambut, dan ditumbuhi vegetasi, yang merupakan suatu ekosistem (PP RI No 73, 2013). Lahan rawa merupakan salah satu lahan sub optimal yang layak dikembangkan untuk pertanian. Di Indonesia, terdapat hampir 30\% dari 33,4 juta ha lahan rawa layak dikembangkan untuk budidaya pertanian 
(Haryono, 2012). Lahan rawa tersebut tersebar di seluruh pulau di Indonesia termasuk Pulau Kalimantan sebagai salah satu pemilik lahan terbesar (Ritung, 2011). Berdasarkan pengaruh pasang surut, lahan rawa dibagi menjadi 2 zona yaitu lahan rawa pasang surut dan non pasang surut atau rawa lebak. Lahan rawa pasang surut dipengaruhi oleh gerakan air pasang surut laut dan atau sungai, baik langsung maupun tidak langsung, dan merupakan lahan rawa dominan yang ada di Indonesia. Berdasarkan perbedaan topografinya, lahan rawa pasang surut dibagi menjadi beberapa tipe luapan air: (1) Tipe luapan A, yaitu lahan yang terluapi oleh pasang besar dan kecil, (2) Tipe luapan B, yaitu lahan yang terluapi oleh pasang besar saja, (3) Tipe luapan $\mathrm{C}$, yaitu lahan yang tidak terluapi air pasang, tetapi tinggi muka airnya dangkal, dan (4) Tipe luapan D, yaitu lahan yang tidak terluapi air pasang dan tinggi muka airnya dalam (BBSDLP, 2006).

Pengembangan pertanian di lahan rawa pasang surut merupakan salah satu hal yang mutlak perlu dilakukan. Lahan pasang surut telah menjadi sumber pencaharian penting bagi masyarakat sekitarnya (Sahuri dkk., 2014). Kebutuhan beras di Indonesia diperkirakan meningkat sampai $2 \%$ setiap tahunnya. Di sisi lain, terjadi penurunan lahan subur pertanian di Pulau Jawa, akibat konversi lahan yang juga meningkat setiap tahunnya (Haryono, 2012). Produktivitas padi di Indonesia juga dilaporkan semakin mengalami penurunan (Kusnadi dkk., 2011). Padahal potensi lahan rawa pasang surut di Indonesia masih sangat besar. Luas lahan rawa pasang surut yang dapat dijadikan lahan pertanian sekitar 9.45 juta ha, tetapi baru 4.2 juta ha yang telah direklamasi dan dimanfaatkan baik oleh petani lokal, penempatan areal transmigrasi, dan petani pendatang lainnya (Nugroho dkk., 1993).

Pemanfaatan lahan rawa pasang surut untuk pertanian memang tidak semudah yang diharapkan karena dipengaruhi oleh beberapa hal. Waktu tanam adalah salah satu faktor penentu kebehasilan budidaya pertanian di lahan rawa pasang surut. Waktu tanam tanaman pangan terutama padi mempunyai peranan yang sangat penting pada produksi akhir hasil pertanian (Runtunuwu dkk., 2011). Penggeseran waktu tanam walaupun hanya sekitar 10 hari (dasarian) berpotensi untuk menurunkan hasil sampai 40\% (Irianto, 2000). Di Indonesia saat ini dikenal 3 Musim Tanam (MT), yaitu: (a) MT I atau musim hujan $(\mathrm{MH})$, antara bulan November sampai Pebruari; (b) MT II atau musim kemarau I (MK-I), juga disebut musim gadu, antara bulan Maret sampai Juni; dan (c) MT III atau musim kemarau II (MK-II), antara bulan Juli sampai Oktober. Adanya dinamika perubahan iklim seperti periode kekeringan (tahun El Nino) dan atau 
kebasahan (tahun La Nina) yang tidak menentu, berimbas pada pergeseran awal dan akhir musim tanam serta berdampak negatif bagi produktivitas tanaman, khususnya tanaman padi (Runtunuwu dkk., 2012). Analisis tentang waktu tanam padi di lahan rawa pasang surut Pulau Kalimantan di tengah perubahan iklim perlu dilakukan dengan adanya hal tersebut. Diharapkan lahan rawa pasang surut dapat dijadikan sebagai salah satu alternatif lumbung pangan menghadap perubahan iklim di Indonesia, terutama di Pulau Kalimantan.

\section{METODE}

Analisis waktu tanam dilakukan pada tahun 2011 sampai tahun 2012, di sawah rawa pasang surut hingga tingkat kecamatan di Pulau Kalimantan. Analisis dilakukan melalui 2 tahap:

1. Analisis data sekunder, meliputi: 1) Data luas tanam 10 tahun terakhir (20002010) dari Badan Pusat Statistik (BPS);

2) Data curah hujan harian selama 10 tahun terakhir (2001-2010) lahan rawa lebak pulau Kalimantan dari stasiun iklim Badan Meteorologi, Klimatologi dan Geofisika (BMKG), Kementerian Pekerjaan Umum (PU) dan Balai Proteksi Tanaman Pangan dan Hortikultura (BPTPH) di Pulau Kalimantan; 3) Data prediksi sifat hujan musim tanam 2011/2012 dari BMKG;
2. Survei acak daerah pertanaman padi dan wawancara dengan petani di lapangan. Data primer hasil wawancara petani meliputi tinggi muka air atau genangan, puncak tanggal tanam, rotasi tanaman dan intensitas tanam.

3. Analisis waktu tanam menggunakan data dasarian atau 10 harian, dimulai dari bulan Januari sampai Desember dengan total 36 dasarian. Data dasarian digunakan untuk penetapan waktu tanam karena mengikuti rentang waktu dasarian data curah hujan yang berkaitan erat dengan musim tanam. (BMKG, 2014).

4. Analisis neraca beras di Pulau Kalimantan. Data yang digunakan adalah luas panen atau produksi padi Pulau Kalimantan dari BPS.

Bagan alur analisis dinamika waktu tanam padi di sawah lahan rawa Pulau Kalimantan disajikan pada Gambar 1.

\section{HASIL DAN PEMBAHASAN}

\section{Luas lahan sawah pasang surut di rawa pulau Kalimantan}

Total luas lahan sawah di Pulau Kalimantan sekitar 2.798.749 ha, dimana sekitar 394.910 ha berada di ekosistem rawa yang tujuh puluh delapan persennya adalah sawah rawa pasang surut, sisanya berada di ekosistem rawa lebak dan polder lainnya (Analisis data BPS, 2011). Luas sawah pasang surut terluas di dimiliki oleh 
Provinsi Kalimantan Selatan, diikuti Provinsi Kalimantan Tengah, Kalimantan Barat, dan Kalimantan Timur. Sawah pasang surut di Kalimantan Selatan luas lahan terluas di Kecamatan Tabunganen, Barito Kuala (Tabel 1). Puncak tanam pada bulan Maret di Kalimantan Selatan seluas 96.164 ha, di Kalimantan Tengah mencapai 77.235 ha, diikuti Kalimantan Barat seluas 57.637 ha, dan Kalimantan Timur seluas 7.527 ha (Analisis data BPS, 2011).

Lahan sawah di seluruh Provinsi Pulau Kalimantan lebih banyak diusahakan di rawa pasang surut, meskipun dari sisi kesuburan tanah lahan pasang surut bersifat sangat masam, kahat unsur Fe, pirit tinggi, dan dapat bersifat salin ketika musim kemarau panjang. Instrusi air laut yang terus-menerus dan tidak dapat dinetralkan kembali dengan keberlimpahan air dari daerah hulu menyebabkan lahan sawah mencapai 168.826 ha (Gambar 2), dengan

pasang surut tipe luapan A berubah fungsi menjadi tambak, seperti yang terjadi di Rawa Seragi, Lampung Selatan, serta di Provinsi lainnya yang memiliki rawa. Intrusi air laut dan berkurangnya ketersediaan air segar untuk irigasi menyebabkan banyak lahan sawah pasang surut yang semula dapat ditanami dua kali, menjadi hanya dapat ditanami satu kali dalam setahun, seperti banyak terjadi di Tarantang, Kabupaten Barito Kuala. Keengganan masyarakat menggunakan pola tanam sawit dupa (unggul-lokal) dalam bertanam padi dan ditambah dengan peluang keuntungan yang lebih besar apabila hamparan sawah pasang surut diubah menjadi sistem surjan dengan pertanaman jeruk/karet/dan tanaman buah/horti lainnya juga menjadikan banyak hamparan sawah di rawa pasang surut hanya dapat ditanami satu kali dalam setahun.

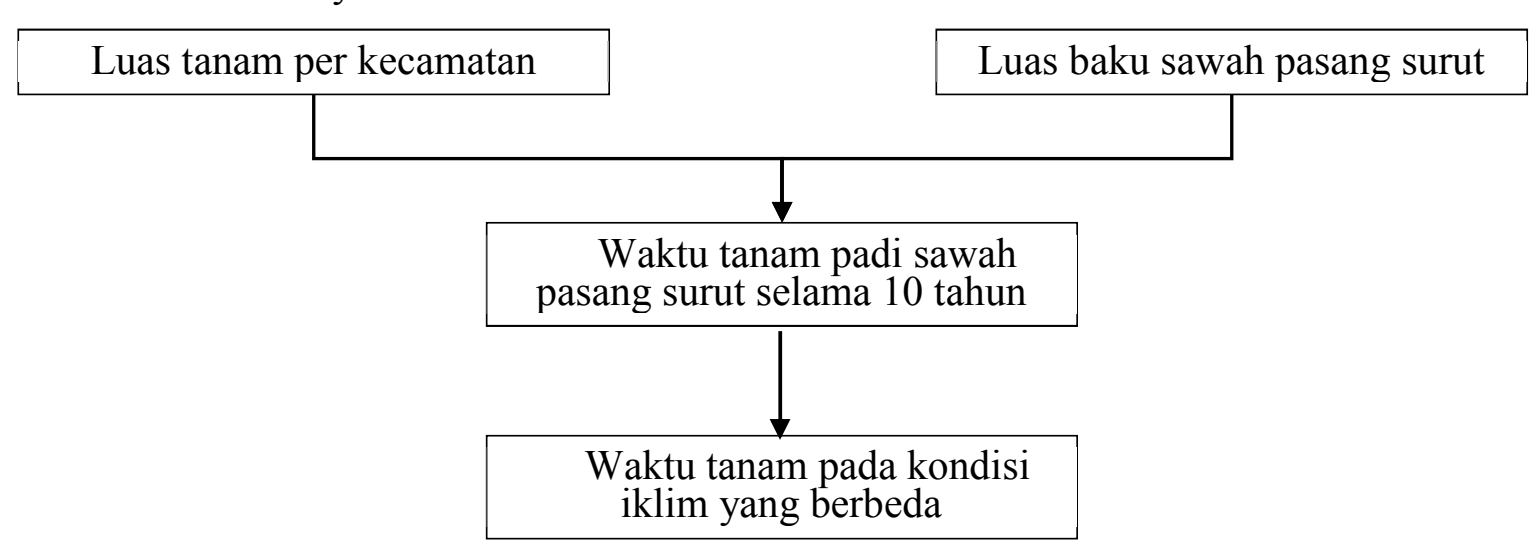

Gambar 1. Bagan alur analisis waktu tanam padi di sawah rawa pasang surut Pulau Kalimantan. 


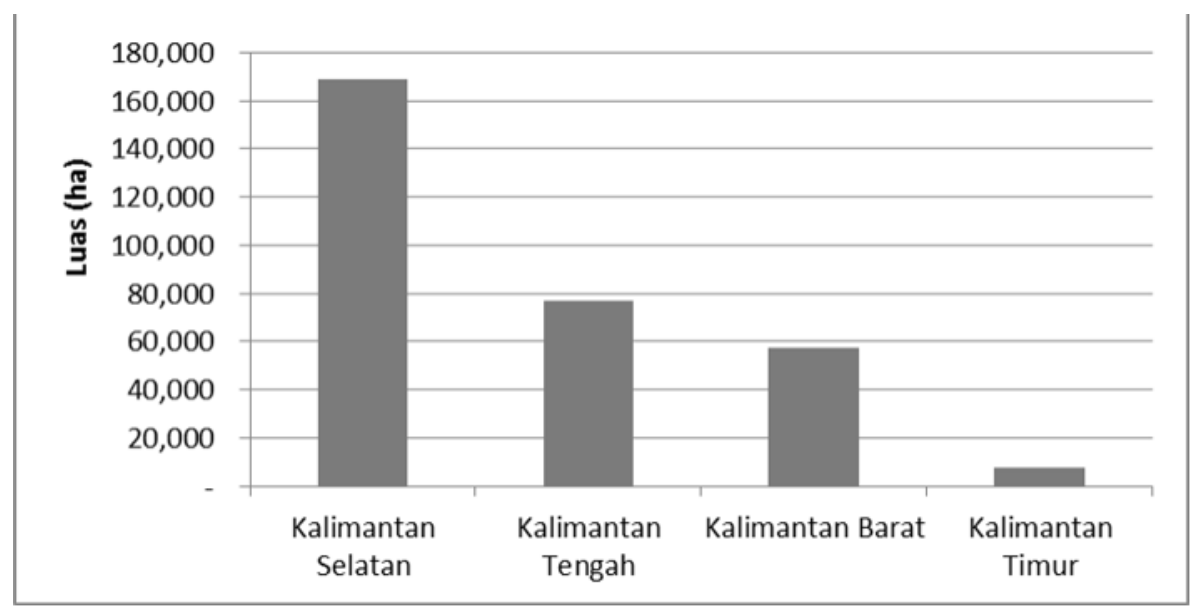

Gambar 2. Luas sawah pada ekosistem rawa seluruh provinsi di Pulau Kalimantan

Tabel 1. Luas lahan sawah terluas pada ekosistem rawa pasang surut di Pulau Kalimantan

\begin{tabular}{lllc}
\hline \multicolumn{1}{c}{ Provinsi } & \multicolumn{1}{c}{ Kabupaten } & \multicolumn{1}{c}{ Kecamatan } & Pasang Surut \\
\hline Kalimantan Barat & Kubu Raya & Sungai Kakap & 10.770 \\
Kalimantan Selatan & Barito Kuala & Tabunganen & 12.517 \\
Kalimantan Tengah & Kapuas & Selat & 17.045 \\
Kalimantan Timur & Bulongan & Tanjung Palas Tengah & 1.535 \\
\hline
\end{tabular}

Lahan sawah di seluruh Provinsi

Pulau Kalimantan lebih banyak diusahakan di rawa pasang surut, meskipun dari sisi kesuburan tanah lahan pasang surut bersifat sangat masam, kahat unsur Fe, pirit tinggi, dan dapat bersifat salin ketika musim kemarau panjang. Instrusi air laut yang terus-menerus dan tidak dapat dinetralkan kembali dengan keberlimpahan air dari daerah hulu menyebabkan lahan sawah pasang surut tipe luapan $\mathrm{A}$ berubah fungsi menjadi tambak, seperti yang terjadi di Rawa Seragi, Lampung Selatan, serta di Provinsi lainnya yang memiliki rawa. Intrusi air laut dan berkurangnya ketersediaan air segar untuk irigasi menyebabkan banyak lahan sawah pasang surut yang semula dapat ditanami dua kali, menjadi hanya dapat ditanami satu kali dalam setahun, seperti banyak terjadi di
Tarantang, Kabupaten Barito Kuala. Keengganan masyarakat menggunakan pola tanam sawit dupa (unggul-lokal) dalam bertanam padi dan ditambah dengan peluang keuntungan yang lebih besar apabila hamparan sawah pasang surut diubah menjadi sistem surjan dengan pertanaman jeruk/karet/dan tanaman buah/horti lainnya juga menjadikan banyak hamparan sawah di rawa pasang surut hanya dapat ditanami satu kali dalam setahun.

\section{Waktu tanam sawah lahan rawa pasang surut}

Penetapan waktu tanam di lahan rawa ini menggunakan luas lahan sawah rawa yang ada pada masing-masing tipologi lahan. Luasan yang berubah-ubah mengikuti pola fluktuasi pasang naik dan pasang surut muka air laut pada rawa 
p-ISSN: 1410-0029; e-ISSN2549-6786

Agrin Vol. 22, No. 2, Oktober 2018

pasang surut menyebabkan luas baku sawah sawah di rawa pasang surut dan lebak per ini juga berubah-ubah. Pada analisis ini, kecamatan tahun 2010.

data yang digunakan adalah luas lahan

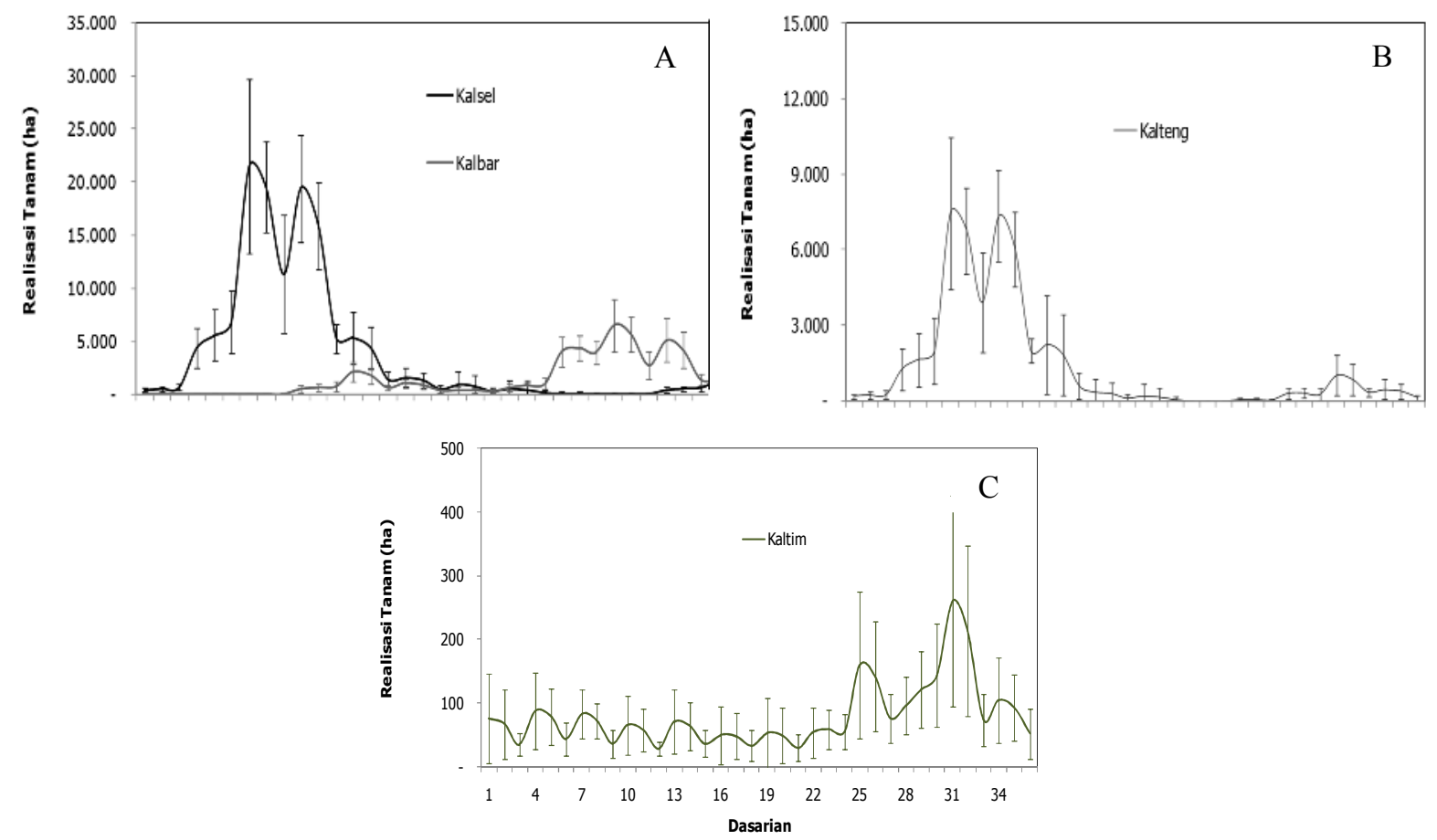

Gambar 3. Pola realisasi tanam dasarian padi pada lahan sawah pasang surut di Kalimantan, periode 2000-2010. A. Kalimantan Selatan dan Kalimantan Barat, B. Kalimantan Tengah dan C. Kalimantan Timur.

Realisasi waktu tanam padi sawah rawa pasang surut di Pulau Kalimantan menunjukkan pola yang cukup berbeda, apalagi dibanding waktu tanam lahan rawa lebak (Wakhid dan Syahbuddin, 2015). Waktu tanam puncak di Propinsi Kalimantan Selatan mirip dengan pola di Kalimantan tengah dimana realisasi waktu tanam terbanyak terjadi pada kisaran dasarian 7-10 atau sekitar bulan MaretApril. Pola ini berlawanan dengan waktu tanam di Propinsi Kalimantan Barat dan Kalimantan Timur, dimana waktu tanam dominan terjadi pada dasarian 30-33 atau sekitar bulan Oktober-November (Gambar
3). Pada dasarnya realisasi tanam petani di sawah rawa pasang surut terjadi setelah kejadian hujan yang diperkirakan cukup untuk pengairan sekaligus cukup untuk melarutkan kadar besi di dalam air.

Waktu tanam di Kalimantan Selatan dan Kalimantan Tengah dimulai sekitar bulan Maret dimana sifat asam telah larut setelah terjadinya curah hujan yang cukup lama. Luas sawah pasang surut di Kalimantan Selatan dan Tengah juga lebih luas dibanding Kalimantan Barat maupun Timur, sehingga kemungkinan penanaman setelah menunggu curah hujan beberapa waktu menjadi sangat rasional. Jenis sawah 
pasang surut yang dominan di Kalimantan Selatan dan Tengah adalah sawah pasang surut tipe A dan B (BBSDLP, 2006), dimana curah hujan yang dibutuhkan lebih besar dan lama dari pada sawah pasang surut tipe $\mathrm{C}$ atau D. Waktu tanam di sawah pasang surut juga dipengaruhi oleh jaringan irigasi atau saluran air sehingga kekuatan pasang surut akan berkurang. Khusus untuk Kalimantan Barat, waktu tanam juga dipengaruhi oleh zona musim, dimana propinsi tersebut termasuk daerah Non Zona Musim (Non ZOM), dimana pada umumnya tidak mempunyai perbedaan yang jelas antara periode musim hujan dan musim kemarau.

Metode tanam juga berpengaruh pada waktu tanam keseluruhan, dimana proses awal tanam di Propinsi Kalimantan Selatan membutuhkan waktu yang cukup lama dalam proses awal tanam. Proses penanaman padi di sawah pasang surut Kalimantan Selatan biasanya menggunakan varietas lokal dengan sistem tanam pindah sebanyak 3 kali penyemaian yaitu persemaian I (taradakan), persemaian II (ampakan), dan persemaian III (lacakan). Selutuh kegiatan ini biasanya membutuhkan waktu sekitar 4 bulan sampai tanaman siap ditanam di lahan sawah pada sekitar bulan Maret. Kegiatan persemaian I (menaradak) dimulai menjelang musim hujan bila tanah sudah mulai basah pada bulan Oktober. Kegiatan persemaian II (maampak) dilakukan setelah umur bibit pada persemaian I sekitar 35-40 hari, yaitu pada bulan Nopember. Bibit tersebut dipindah dan ditanam ke areal petakan persemaian II yang lebih luas dengan harapan bibit menjadi besar dan kuat sekaligus untuk memperbanyak bibit. Kegiatan persemaian III (malacak) dilakukan setelah bibit berada sekitar 35-45 hari pada persemaian ke II (Januari), bibit dicabut dan ditanam pada areal lacakan yang lebih luas agar tanaman cukup mampu mengatasi dinamika tinggi muka air yang cukup tinggi. Lacakan dibiarkan tumbuh selama 50-70 hari sebelum dilakukan penanaman pada areal persawahan pada bulan Maret dan panen pada bulan Agustus.

\section{Waktu tanam padi sawah pasang surut pada tahun dan kondisi iklim yang berbeda}

Lahan rawa pasang surut juga menunjukan tingkat kekukuhan yang tinggi terhadap perubahan iklim. Pola realisasi tanam hanya mengalami pergeseran sedikit sekali ketika terjadi El Nino maupun La Nina (Gambar 4). Secara umum tinggi luapan pasang optimal untuk tanaman padi di sawah $<24 \mathrm{~cm}$. Pada musim hujan luapan air yang dapat ditoleransi padi sekitar $35 \mathrm{~cm}$ dari permukaan tanah. Pada padi lokal, mereka mempunyai mekanisme mempertahankan diri dari genangan air dengan memanjangkan batang melewati permukaan air. Pada padi unggul lahan 

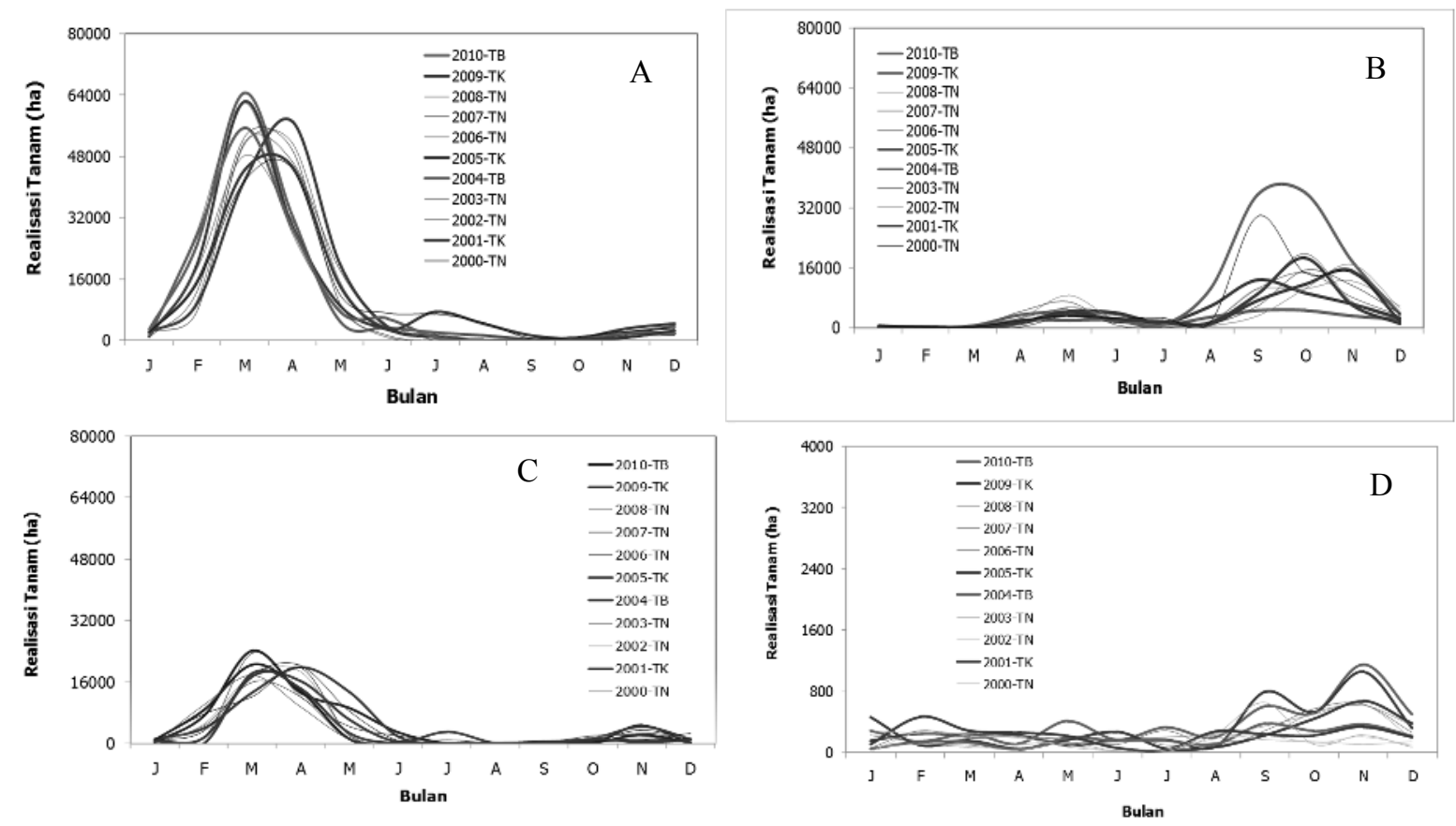

Gambar 4. Pola realisasi tanam dasarian padi pada lahan sawah pasang surut di Kalimantan, periode 2000-2010. A. Kalimantan Selatan (Wakhid, N., dan H. Syahbuddin, 2015), B. Kalimantan Barat, C. Kalimantan Tengah dan D. Kalimantan Timur. TB = tahun basah, TK = tahun kering, $\mathrm{TN}=$ tahun normal.

rawa, rendaman air di atas $35 \mathrm{~cm}$ dapat ditoleransi bila lama genangan tidak melebihi 14 hari. Sementara tinggi muka air tanah yang optimal untuk tanaman padi ialah $<40 \mathrm{~cm}$. Pada kondisi itu perakaran tanaman padi masih dapat menjangkau air untuk memenuhi kebutuhan hidupnya. Tinggi muka air tanah turun atau lebih dalam dari $40 \mathrm{~cm}$ pada saat musim kering. Saat itu perakaran padi tidak lagi dapat menjangkau air, sehingga menjadi faktor pembatas.

Pola tanam masing-masing propinsi di Pulau Kalimantan juga berkaitan erat dengan sifat hujan (ZOM BMKG) di tempat tersebut. Kondisi iklim di Indonesia dipengaruhi oleh fenomena El Nino/La Nina yang bersumber dari wilayah timur
Indonesia (Ekuator Pasifik Tengah/Nino 34) dan Dipole Mode yang bersumber dari wilayah barat Indonesia (Samudera Hindia barat Sumatera hingga timur Afrika). Fenomena regional juga mempengaruhi hal tersebut, seperti sirkulasi monsun AsiaAustralia, daerah pertemuan angin antar tropis atau Inter Tropical Convergence Zone (ITCZ) yang merupakan daerah pertumbuhan awan, serta kondisi suhu permukaan laut sekitar wilayah Indonesia.

Pulau Kalimantan yang meliputi 4 propinsi terdiri dari 22 Zona Musim (ZOM) yaitu nomor 264 sampai dengan 285. Awal musim hujan 2011/2012 pada 22 Zona Musim (ZOM) di Kalimantan diperkirakan berkisar pada bulan Oktober 2011. Sebanyak 3 ZOM, awal musim hujan antara 
dasarian I - III September 2011, meliputi

Ketapang, Kutai, Malinau, dan Kertanegara. Sebanyak 17 ZOM meliputi sebagian besar Kalimantan, awal musim hujan antara dasarian I - III Oktober 2011. Sebanyak 2 ZOM, awal musim hujan antara dasarian I - III Nopember 2011, meliputi Pulau Laut, Tanah Bumbu bagian tengah, dan Pasir bagian timur. Sifat hujan musim hujan 2011/2012 pada 22 Zona Musim di Kalimantan, diperkirakan umumnya Normal (N) hingga Atas Normal (AN). Sebanyak 8 ZOM, sifat hujan musim hujan 2011/2012 Atas Normal, meliputi Kalimantan Timur bagian barat dan selatan, Pulau Laut, Tanah Bumbu bagian tengah, Pasir bagian timur, Barito Kuala, Banjar bagian barat, Tapin bagian selatan, dan Tanah Laut bagian selatan. Sejumlah 14 ZOM lainnya, sifat hujan musim hujan 2011/2012 Normal, meliputi sebagian besar Kalimantan.

Khusus untuk daerah Kalimantan Barat masuk Non Zona Musim (Non ZOM), dimana daerah tersebut pada umumnya tidak mempunyai perbedaan yang jelas antara periode musim hujan dan musim kemarau. Dalam hal ini, daerah yang sepanjang tahun curah hujannya tinggi atau rendah. Berdasarkan data perkiraan hujan BMKG Pontianak tahun 2011/2012, sebagian besar wilayah Kalimantan Barat mempunyai sifat hujan normal kecuali kota
Singkawang yang mempunyai sifat hujan atas normal.

\section{Waktu Tanam Hasil Kuesioner}

\section{Kalimantan Selatan}

Varietas yang dominan digunakan pada lahan rawa pasang surut Kalimantan Selatan adalah varietas lokal seperti Siam yang berumur sekitar 10 bulan dengan sistem tanam pindah sebanyak tiga kali penyemaian, yaitu persemaian I (taradakan), persemaian II (ampakan), dan persemaian III (lacakan). Pada iklim normal (TN), kegiatan persemaian I (menaradak) dimulai menjelang musim hujan bila tanah sudah mulai basah pada bulan Oktober. Kegiatan persemaian II (maampak) dilakukan setelah umur bibit pada persemaian I sekitar 35-40 hari, yaitu pada bulan Nopember. Bibit tersebut dipindah dan ditanam ke areal petakan persemaian II yang lebih luas dengan harapan bibit menjadi besar dan kuat sekaligus untuk memperbanyak bibit. Kegiatan persemaian III (malacak) dilakukan setelah bibit berada sekitar 35-45 hari pada persemaian ke II (Januari), bibit dicabut dan ditanam pada areal lacakan yang lebih luas agar tanaman cukup mampu mengatasi dinamika tinggi muka air yang cukup tinggi. Lacakan dibiarkan tumbuh selama 50-70 hari sebelum dilakukan penanaman pada areal persawahan pada bulan Maret dan panen pada bulan Agustus. 
Adanya curah hujan dibawah normal (TK) menyebabkan terjadinya pergeseran awal persemaian pertama, bergeser ke bulan Nopember, maka terjadi perpendekan waktu bibit berada pada persemaian I, II dan III sehingga tanam tetap bulan Maret, demikian juga dengan adanya curah hujan diatas normal (TB), pergeseran terjadi hanya pada lama bibit berada pada semaian I, II dan III, penanaman tetap dilakukan pada bulan Maret. Pergeseran waktu tanam menjadi Pebruari atau April umumnya disebabkan masalah ketersediaan tenaga kerja atau pada lahan yang airnya sudah surut atau masih terlalu tinggi (terutama pada lahan tipe luapan C).

Padi varietas unggul ditanam hanya sebagian kecil saja, umumnya di persawahan Unit Pemukiman Transmigrasi (UPT) dengan pola sawit dupa (padi lokalpadi unggul). Penanaman padi varietas unggul dilakukan dengan memamfaatkan lahan sisa penyemaian padi lokal (70-80\% dari luas sawah) dan waktu penyemaian I, II dan III padi lokal, yaitu bulan Oktober sd Pebruari tahun berikutnya. Penyemaian padi unggul dilakukan bersamaan dengan penyemaian I pada padi lokal yaitu setelah tanah mulai basah (Oktober) dan penanaman dilakukan pada bulan Nopember serta panen pada akhir bulan Pebruari sehingga pada bulan Maret sudah bisa dilakukan tanam padi lokal.
Adanya curah hujan dibawah normal (TK) dan bila menyebabkan terjadinya pergeseran awal musim hujan, maka penyemaian bergeser sesuai dimulainya awal musim hujan dan secara otomatis akan menggeser waktu tanam dan waktu panen, tetapi pergeseran tidak terlalu lama karena curah hujan yang rendah pada fase pemasakan akan mempercepat proses pemasakan gabah sekitar 7-10 hari. Sedangkan adanya curah hujan diatas normal (TB) menyebabkan ketinggian muka air meningkat dan kesulitan tanam terutama pada lahan tipe B yang sistem drainasenya kurang lancar dan pada lahan tipe luapan C. Ketinggian maksimum luapan air pasang surut berkaitan dengan curah hujan kawasan. Pada lahan tipe D, jarang dimanfaatkan untuk tanam padi, hanya sebgian kecil bertanam padii gogo, saat tanam tergantung awal musim hujan, umumnya pada bulan Oktober untuk TB dan Nopember untuk TN dan Desember untuk TK.

\section{Kalimantan Barat}

Pada lahan pasang surut tipe luapan A (diwakili lokasi Siantan, Kab Pontianak) puncak tanam pada tahun kering jatuh bulan November, tahun basah jatuh bulan Juli dan tahun normal juga jatuh pada bulan Juli, sedangkan pada tipe luapan B sangat variatif sekali di lokasi Sei Kakap, Kab Kubu Raya puncak tanam pada tahun kering jatuh pada bulan Oktober, Rasau 
Jaya, Kab Kubu Raya jatuh pada bulan September, sementara lokasi Siantan, Kab. Pontianak dan Putusibau, Kab Kapuas Hulu jatuh pada Agustus. Puncak tanam pada tahun basah di lokasi Sei Kakap jatuh pada bulan November - Desember, dan pada tahun normal jatuh pada Desember, sedangkan di lokasi Siantan, Kab Pontianak dan Putusibau, Kab Kapuas Hulu puncak tanam tahun basah dan normal sama-sama jatuh pada bulan September.

Pada lahan rawa pasang surut tipe luapan $\mathrm{B} / \mathrm{C}$ masing-masing puncak tanam pada lokasi Semangau, Kab Sambas pada tahun kering jatuh pada bulan November, tahun basah dan tahun normal jatuh pada bulan yang sama November, sedangkan pada Sei Raya, Kab. Bengkayang pada tahun kering, tahun basah dan normal jatuh pada November. Pada lahan rawa pasang surut tipe luapan C pada Kab. Sintang puncak tanam pada tahun kering jatuh pada Agustus, pada tahun basah jatuh bulan September dan pada tahun normal jatuh pada bulan Oktober, sedang pada lokasi Tebas Kab Sambas puncak tanam pada tahun kering jatuh pada November, pada tahun basah dan tahun normal juga jatuh pada bulan November. Puncak tanam menunjukan semakin ke belakang atau melambat seiring dengan tipe luapannya atau dengan kata lain puncak tanam pada tipe luapan B lebih awal dibanding luapan C dan A pada tahun kering, tetapi tipe luapan A berturutan lebih awal daripada tipe $\mathrm{B}, \mathrm{B} / \mathrm{C}$ dan $\mathrm{C}$ pada tahun normal. Hal serupa juga terjadi di Kalimantan Selatan dimana tanam lebih awal pada tipe luapan A menyusul $B$ dan $C$ pada tahun-tahun normal.

\section{Kalimantan Tengah}

Pada lahan rawa pasang surut tipe A di Kabupaten Kapuas puncak waktu tanam musim hujan (MH) pada tahun kering (TK) terjadi pada sepuluh hari terakhir bulan Maret hingga sepuluh hari pertama bulan April (Maret III/April I). Pada lahan pasang surut tipe B puncak waktu tanam $\mathrm{MH}$ pada TK terjadi pada Maret III. Artinya baik lahan pasang surut tipe A maupun B mempunyai kelompok waktu tanam yang sama yaitu Maret III/April I, kemudian di lahan pasang surut tipe $\mathrm{C}$ puncak waktu tanam MH pada TK terjadi pada Februari II, sedangkan pada MK I terjadi pada September II untuk IP-200. Kondisi ini menunjukkan bahwa semakin tinggi posisi lahan, maka waktu tanam MH pada TK lebih cepat. Kasus yang sama juga terjadi di Kecamatan Kahayan Hilir, Kabupaten Pulang Pisau. Berbeda dengan di Desa Blanti Siam, Kecamatan Pandihbatu, di mana puncak waktu tanam MH (TK) terjadi pada Oktober II/III, sedangkan pada MK I terjadi pada Juli I/II untuk IP 200. Perbedaan ini disebabkan karena perbedaan sistem tata air yang digunakan. Di Blanti Siam sistem tata air yang digunakan adalah 
sistem pipanisasi, sehingga pengelolaan airnya lebih mudah dilakukan dan sistem tanam tabela (tanam benih langsung).

Daerah Teluksampit, Kotawaringin Timur, lahan pasang surut tipe A puncak waktu tanam MH (TK) terjadi pada September III/Oktober I dan Januari III/Februari I, sedangkan lahan pasang surut tipe B terjadi pada Oktober II/III dan Maret III/April I. Puncak tanam di Teluksampit lebih cepat dibandingkan lokasi lain karena lokasi dekat pantai, sehingga untuk menghindari kegagalan panen akibat intrusi air asin waktu tanam dimajukan. Di Kotawaringin Barat puncak waktu tanam MH (TK) pada lahan pasang surut tipe A terjadi pada Oktober II/III, sedangkan pada lahan pasang surut tipe $\mathrm{B}$ dan $\mathrm{C}$ tidak ditanami akibat kekeringan. Di lihat dari topografi lahan di Kotawaringin Barat lebih tinggi dibandingkan dengan Kapuas, Pulangpisau, dan Kotawaringin Timur.

Puncak waktu tanam MH (TN) pada lahan pasang surut tipe A rata-rata maju 1 dasarian, karena tidak bisa dilakukan tanam akibat genangan air masih tinggi. Begitu juga dengan puncak tanggal tanam $\mathrm{MH}$ (TB) maju 2 - 3 dasarian. Kondisi yang sama juga terjadi pada lahan pasang surut tipe B dan tipe C. Perbedaan ini disebabkan karena perbedaan tinggi genangan air.

\section{Kalimantan Timur}

Puncak tanggal tanam musim hujan pada tahun kering (TK) di lahan pasang surut tipe luapan A Kalimantan Timur adalah pada bulan Desember minggu kedua (Desember II) sampai bulan Pebruari minggu pertama (Pebruari I). Adanya perbedaan puncak tanggal tanam ini disebabkan letak persawahan dari sungai, ada tidaknya saluran primer, dan terpeliharanya saluran-saluran yang telah dibuat. Persawahan yang terletak relatif lebih jauh dari sungai dan saluran air yang kurang baik lebih menunda saat pertanaman sehingga puncak tanggal tanamnya juga tertunda. Pada musim tanam kedua, puncak tanggal tanam berkisar antara Mei II sampai Juni II. Perbedaan ini juga disebabkan seperti pada pertanaman pertama, yaitu faktor letak persawahan, ada tidaknya saluran air, dan terpeliharanya saluran air tersebut.

Pada tahun normal (TN), puncak tanggal tanam musim hujan pada tipe luapan A pada bulan Desember minggu ketiga (Desember III) sampai Pebruari minggu kedua (Pebruari II). Sedangkan pada musim tanam kedua terjadi pada bulan Mei minggu keempat (Mei IV) sampai Juni minggu kedua (Juni II). Sama seperti pada tahun kering, ada perbedaan puncak tanggal tanam di persawahan yang disebabkan oleh letak persawahan dari sungai, ada tidaknya saluran primer, dan terpeliharanya saluransaluran yang telah dibuat.

Pada tahun basah (TB), puncak tanggal tanam musim hujan pada tipe 
luapan A terjadi pada bulan Desember minggu keempat (Desember IV) sampai Pebruari minggu ke tiga (Pebruari III). Pada musim tanam kedua, puncak tanam pada bulan Juni minggu kedua (Juni II) sampai Juni minggu ke keempat (Juni IV). Perbedaan puncak tanggal tanam ini juga disebabkan oleh letak persawahan dari sungai, ada tidaknya saluran primer, dan terpeliharanya saluran-saluran yang telah dibuat. Puncak tanggal tanam pada tahun kering nampaknya lebih awal sekitar satu minggu dibandingkan dengan tahun normal, sedangkan puncak tanggal tanam pada tahun basah lebih lambat sekitar satu minggu pula dibanding tahun normal. Terlihat bahwa ketersediaan air dari curah hujan sangat menentukan puncak tanggal tanam.

Pada lahan pasang surut tipe luapan $\mathrm{B}$, puncak tanggal tanam musim hujan pada tahun kering (TK) adalah pada bulan Nopember minggu kedua (Nopember II) sampai bulan Januari minggu pertama (Januari I). Pada musim tanam kedua, puncak tanggal tanam pada bulan Mei minggu kedua (Mei II) sampai Juni minggu kedua (Juni II). Pada tahun normal (TN), puncak tanggal tanam musim hujan pada tipe luapan B pada bulan Desember minggu pertama (Desember I) sampai Desember minggu keempat (Desember IV). Pada musim tanam kedua terjadi pada bulan Mei minggu kedua (Mei II) sampai Juni minggu keempat (Juni IV). Pada tahun basah (TB), puncak tanggal tanam musim hujan pada bulan Desember minggu kedua (Desember II) sampai Januari minggu pertama (Januari I). Pada musim tanam kedua, puncak tanam pada bulan Juni minggu pertama (Juni I) sampai Juli minggu kedua (Juli II). Perbedaan puncak tanggal tanam pada tipe luapan B, baik pada musim hujan (musim tanam pertama) maupun pada musim kemarau tanam (musim tanam kedua) disebabkan oleh letak persawahan dari sungai besar. Faktor lain ditentukan oleh ada tidaknya saluran primer, dan terpeliharanya saluran-saluran yang telah dibuat tersebut. Persawahan yang terletak relatif lebih jauh dari sungai dan saluran air yang tidak dipelihara dengan baik akan menunjukkan puncak tanggal tanam lebih lambat dibandingkan dengan persawahan yang lebih dekat dengan sungai dan memiliki saluran air yang terpelihara dengan baik. Puncak tanggal tanam pada tahun kering pada tipe luapan B nampaknya juga lebih awal sekitar dua sampai tiga minggu dibandingkan dengan tahun normal, sedangkan puncak tanggal tanam pada tahun basah lebih lambat sekitar dua minggu dibanding tahun normal. Nampaknya ketersediaan air yang berasal dari curah hujan sangat menentukan puncak tanggal tanam di lahan pasang surut tipe luapan B. Pada tahun kering pertamanan dilakukan lebih awal untuk menghindari 
periode kekeringan pada saat tanaman padi memasuki periode reproduktif. Jika terlambat tanaman berisiko gagal panen akibat gabah puso yang disebabkan oleh ketidaktersediaan air menjelang fase berbunganya. Pada tahun basah, penanaman lebih lambat karena kondisi persawahan tergenang cukup tinggi sehingga diperlukan waktu menunggu surutnya air agar bisa dimulai saat tanam bibit padi.

\section{KESIMPULAN}

Waktu tanam di lahan pasang surut dimulai setelah jumlah air hujan mencukupi untuk melarutkan kadar besi yang ada di dalam air. Di Provinsi Kalimantan Barat umumnya realisasi tanam terjadi pada Dasarian 28 (Oktober). Di Kalimantan Timur pada Dasarian 31 (November). Sementara di Kalimantan Selatan dan Kalimantan Tengah umumnya penanaman pada Dasarian 7 (Maret).

Waktu tanam di lahan rawa pasang surut menunjukkan tingkat kekukuhan yang tinggi terhadap perubahan iklim, dimana waktu tanam tidak terlalu berubah selama 10 tahun pada kondisi iklim yang berbeda.

\section{DAFTAR PUSTAKA}

Balai Besar Penelitian dan Pengembangan Sumberdaya Lahan Pertanian (BBSDLP). 2006. Karakteristik dan pengelolaan lahan rawa. Bogor. BBSDLP.
BMKG. 2014. Sifat musim hujan 20112012. Jakarta. BMKG.

BPS. 2011. Kalimantan dalam angka. BPS Kalimantan.

Haryono. 2012. Lahan rawa lumbun pangan masa depan Indonesia. Jakarta. IAARD Press.

Irianto, G., L.I. Amien, dan E. Surmaini. 2000. Keragaman iklim sebagai peluang diversifikasi sumber daya lahan Indonesia. Pusat Penelitian Tanah dan Agroklimat. Badan Penelitian dan Pengembangan Pertanian. Bogor.

Kusnadi, N., N. Tinaprillia, S.H. Susilowati, A. Purwoto. 2011. Analisis efisiensi usahatani padi di beberapa sentra produksi padi di Indonesia. Jurnal Agroekonomi, 29(1): $25-48$.

Nugroho, K. Alkusuma, Paidi, Wahyu Wahdini, Abdulrachman, H. Suhardjo dan IPG. Widjaja Adhi. 1993. Peta area potensial untuk pengembangan pertanian lahan rawa pasang surut, rawa dan pantai. Proyek Penelitian Sumber Daya Lagan, Pusat Penelitian Tanah dan Agroklimat, Badan Litbang Pertanian. Departemen Pertanian.

Peraturan Pemerintah Republik Indonesia Nomor 73 Tahun 2013 tentang rawa.

Ritung, S. 2011. Karakteristik dan sebaran lahan sawah di Indonesia. Hlm 83-98. Dalam. Prossiding Seminar Nasional Teknologi Pemupukan dan Pemulihan lahan Terdegradasi. Balai Penelitian dan Pengembangan Sumberdaya Lahan Pertanian. Bogor.

Runtunuwu E., H. Syahbuddin dan W.T. Nugroh. 2011. Delinasi Kalender Tanam Tanaman Padi Sawah Untuk Antisipasi Anomali Iklim Mendukung Program Peningkatan produksi Beras Nasional. Jurnal Pangan, 20(4): 341 - 356. 
Runtunuwu E., H. Syahbuddin, F. Ramadhani dan W. T. Nugroh. 2012. Dinamika Kalender Tanam Padi di Sulawesi. Jurnal Pangan, 21(2): 113 $-124$.

Sahuri, C.T. Stevanus, dan M.J. Rosyid. 2014. Potensi Pemanfaatan Lahan dan Perbaikan Kultur Teknis Lahan Rawa Pasang Surut untuk Tanaman Karet di Desa Riding, Kabupaten
Ogan Komering Ilir, Provinsi Sumatera Selatan. Prosiding Seminar Nasional Lahan Suboptimal, 26-27 September, Palembang. 8 hal.

Wakhid, N., dan H. Syahbuddin. 2015. Peta kalender tanam padi lahan rawa lebak di Kalimantan Selatan di tengah perubahan iklim global. Jurnal Ilmiah Geomatika 19(1): 32 - 39. 